\title{
Odessa in fiamme: reflejos cinematográficos de la guerra en el Frente Oriental
}

\author{
Carmen BURCEA \\ Departamento de Lingüística Románica, Lenguas y Literaturas Iberorrománicas e Italiano \\ Universidad de Bucarest \\ carmen.burcea@1ls.unibuc.ro
}

\begin{abstract}
RESUMEN
Odessa in fiamme es la película ganadora del Gran Premio del Festival de Venecia en 1942. Censurada por los comunistas después de 1945 y recuperada de los archivos de Cinecittà en 2002, la película relata algunos episodios de la Segunda Guerra Mundial en el Frente Oriental: desde la invasión de Besarabia por el Ejército Rojo (1940) hasta su rescate y la caída de Odessa (1941). Si bien considerada como una expresión más de la política cultural totalitaria, Odessa in fiamme es una película de referencia en el debate sobre los reflejos de la guerra en las artes.
\end{abstract}

Palabras clave: Odessa in fiamme, Cineromit, la propaganda de guerra.

\section{Odessa in flames: cinematic reflections of the war on the Eastern Front}

\begin{abstract}
Odessa in flames won the Great Prize at the Venice Film festival in 1942. Censored by the Communists after 1945 and discovered in Cinecittà Studios' archive in 2002, the film reveals some episodes of World War II on the Eastern Front: since the invasion of Bessarabia by the Red Army (1940) until its liberation and the fall of Odessa (1941). Although considered as an expression of the totalitarian cultural policy, Odessa in flames is a reference movie in the debate on the reflections of the war in the arts.
\end{abstract}

Keywords: Odessa in fiamme, Cineromit, the war propaganda.

Odessa in fiamme es una película de guerra con sabor a propaganda antisoviética, rodada en junio-julio de 1942. Aunque el esquema maniqueo que emplea -la crítica no disimulada hacia los bolcheviques y la exaltación frente a la victoria del ejército libertador del Eje- se reviste estéticamente, las historias del cine recalcan su sello propagandístico y vinculan su éxito meramente al contexto político-ideológico vigente en aquel entonces. El propósito del presente trabajo consiste precisamente 
en reconstituir aquellas circunstancias histórico-políticas y cinematográficas, para luego relevar su vigor artístico más allá de los palmarios condicionamientos ideológicos.

\section{Marco histórico-político}

Al estallar la Segunda Guerra Mundial, Rumanía afirmó su neutralidad. La animosidad de los países limítrofes no le dejaba alternativa. Con la invasión de Polonia (el 1 de septiembre de 1939) y la derrota de Francia (el 22 de junio de 1940) se desplomó su sistema de alianzas, lo que precipitó las maniobras diplomáticas de sus colindantes. Con el pacto Ribbentropp-Molotov, el dictado de Viena y el tratado de Craiova a Rumanía le fueron raptadas Besarabia, el norte de Bucovina y la región de Hertsa (por la Unión Soviética, el 28 de junio), el norte de Transilvania (por Hungría, el 30 de agosto) y el Cadrilater -la Dobruja meridional- (por Bulgaria, el 7 de septiembre). De esta forma, el Reino de la Gran Rumanía desapareció.

El rey Carlos II designó entonces al general Ion Antonescu como presidente del Consejo de Ministros y este, a fin de reconquistar los territorios invadidos, firmó el Pacto Tripartito (noviembre de 1940) y entró en guerra al lado del Eje (el 22 de junio de 1941). Pero una vez liberada Besarabia, el Führer le exigió al general rumano que cruzara el río Dniéster. Sea por razones estratégico-militares sea por razones políticas, el general consintió hacerlo (Constantiniu 1997: 403-404). Detrás de la tan loada gloria en la batalla de Odessa (agosto-octubre de 1941) -que le dejó sin embargo un sabor amargo al general (Constantiniu 1997: 409)- se sucedieron las derrotas de Moscú y Stalingrado (1941/1943) que sellaron indeleblemente el curso de la historia de Rumanía. El 23 de agosto de 1944, el rey Miguel I, después de dimitir y encarcelar al general Antonescu, cambió el bando de los beligerantes. Por lo tanto, Rumanía participó en dos campañas: en el frente del Este para rescatar Besarabia y Bucovina; y en el frente del Oeste para rescatar Transilvania. Acabada la guerra, se le reconoció exclusivamente la participación al lado del Eje y, por consiguiente, firmó el tratado de paz (Paris, 1947) como país enemigo vencido.

\section{Marco histórico-cinematográfico}

Si bien lacónica, una previa incursión histórico-cinematográfica advierte cómo el cine se convirtió en una poderosa herramienta de los «dictadores de celuloide». A partir de los años treinta del siglo pasado y sobre todo durante la Segunda Guerra Mundial -lapso temporal que coincide asimismo con la organización del cine rumano ${ }^{1}$ - Rumanía fue un escenario más para la representación de la política cultural ale-

${ }^{1}$ En 1933, el cine se integra en la Subsecretaría de Estado, junto con el turismo y la radiodifusión; en 1936, se crea la Oficina Nacional del Turismo, con un servicio cinematográfico guiado por el cineasta Paul Călinescu; en 1938, la ONT se integra en el Ministerio de la Propaganda Nacional; en 1940, 
mana e italiana. Escrutar la cooperación cinematográfica con los países aliados resulta por lo tanto imprescindible para perfilar el contexto de la producción de Odessa in fiamme.

En Alemania, la UFA (Universum Film Aktiengeselleschaft) -creada en 1917 para contrarrestar la influencia propagandística norteamericana en Europa- seguía su destino, ilustrando los éxitos bélicos del Tercer Reich en sus noticiarios de guerra. En lo que concernía al cine, una obra cumbre como El gabinete del doctor Caligari (Robert Wiene, 1920) no iba a repetirse pronto. El séptimo arte vivía un momento de ruptura y declive como consecuencia de la ideología nacional-socialista, de la emigración de varios cineastas alemanes y del exilio de los directores y actores judíos (Krakauer 1947; Sadoul 1961; Hull 1969). Mensaje político y arte cinematográfico formaban innegablemente una simbiosis. La función ideológica de las películas constaba sustancialmente en justificar la persecución de los judíos $-E l$ judio eterno (Fritz Hippler, 1940), El judio Süß (Veit Harlan, 1940)- y exaltar el militarismo prusiano -Fridericus (Johannes Meyer, 1936)-.

Mientras Adolf Hitler se limitó a ser cinéfilo y admirador de los directores de cine oficiales -Leni Riefenstahl (Triumpf des Willens, 1934; Olympia, 1938) y Karl Ritter (Kadetten, 1941; Stukas, 1941)- el ministro de la Propaganda, Joseph Goebbels, intuyendo la fuerza de la imagen cinematográfica, creó Reichsfilmkammer (1933) (Goebbels 1984: 382) y, años más tarde, Internazionale FilmKammer (1941) como instrumentos de control político sobre la industria cinematográfica. No obstante, el ideal de Goebbels, el de plasmar «un nuevo Potemkin» alemán, estaba destinado al fracaso.

La cumbre de la cooperación cinematográfica rumano-alemana fue Ciuleandra (Martin Berger, 1930), trasposición de la novela homónima de Liviu Rebreanu, la primera película rumana sonora, reputada por la crítica como «un fiasco artístico» (Ion Cantacuzino 1965). Sin embargo, Odessa in fiamme (1942) -la coproducción italiano-rumana - fue exaltada por la crítica de la época y galardonada en la décima edición del Festival de Venecia.

En Italia, el cine estaba vinculado al régimen fascista de Benito Mussolini. Galeazzo Ciano, homólogo de Goebbels, percibía el cine como «el arma más fuerte de la propaganda». Cinegiornali del Instituto LUCE (L'unione per la cinematografia educativa, 1924) (Brunetta 1975; Argentieri 1977) ilustraban los progresos de Italia, cuyo artífice supremo era il Duce, una superestrella representada en las más diversas hipóstasis: presidente del Consejo de Ministros, pater familias, a caballo, segando, nadando, pilotando, predicando, etc. (Argentieri 1977: 38-39). A diferencia de Hitler, Mussolini no era solo protagonista, sino también supervisor: basta recordar su aporte al rodaje de Campo di maggio (Gioacchino Forzano, 1935) o Scipione l'Africano (Carmine Gallone, 1937).

se les prohíbe a los judíos poseer cualquier instrumento de propaganda (DL, n. 2560, 8/08/1940); en 1941 se crea la Oficina Nacional Cinematográfica (M.O, n. 82, 5/04/1941); en 1943, se crea Cineromit, sociedad cinematográfica italiano-rumana. 
La década de los años treinta marca sin embargo un vuelco en el destino del cine italiano con la institución del Festival de Venecia (1932), por iniciativa de Luciano de Feo; de la Dirección General de Cine (1934), guiada por Luigi Freddi; del Centro Experimental de Cinematografía (1935), dirigido por Luigi Chiarini; de los estudios Cinecittà (1937) -los más modernos de Europa-. De la primera época dorada del cine italiano, habían quedado -según el reputado historiador cinematográfico Georges Sadoul- solo dos representantes: Augusto Genina y Carmine Gallone (Sadoul 1961: 101). Al éxito de Odessa in fiamme iban a contribuir todas estas piezas del gran engranaje del cine italiano.

Las proyecciones del Eje Roma-Berlín en las pantallas rumanas se intensificaron tras la firma del Pacto Tripartito (1940). El mercado cinematográfico rumano se disputaba entre la UFA y LUCE: «El pequeño segmento de la fortuna del cine demuestra que el Pacto de Acero (1939) y las cercanías ideológicas no impidieron irritaciones de índole estratégica entre italianos y alemanes» (Argentieri 1986: 149).

El diplomático italiano Amor Bavay anotaba esa rivalidad: «Se nota un nerviosismo creciente de los órganos alemanes encargados de la propaganda y la difusión del cine alemán en este país, dada la afirmación segura del cine italiano» (Burcea 2008: 57).

Y las anotaciones del ministro alemán, J. Goebbels, lo confirman: «[...] compruebo el estatuto de la Cámara Cinematográfica Internacional -creada en julio de 1941-. Bien delineado. Debemos concentrarlo todo a Berlín, aunque los italianos protesten. Somos nosotros el gran poder del cine europeo» (Goebbels 1984: 322).

Más o menos velada, entre los aliados había una lucha por la supremacía en el campo del cine. Precisamente en este contexto, la Oficina Nacional de Cinematografía (ONC) entablaba tratativas con su equivalente italiano, LUCE, selladas con la creación de Cineromit -sociedad cinematográfica italiano-rumana cuya sede se proyectaba en Bucarest, a orillas del lago de Fundeni (en tierras del boyardo Maican)-. En su diario, Goebbels desvela su ira: «Los italianos nos crean dificultades de todo tipo. Ahora están a punto de crear una casa de producción en Bucarest [...]. Quieren, a todo costo, una rebanada del pastel» (Argentieri 1986: 135).

Hasta aquel entonces, Rumanía había sido una presencia exitosa en el Festival de Venecia, siendo dúplice ganadora del Gran Premio por el film documental -el etnográfico Țara moților (1939) y el bélico România în lupta contra bolșevismului (1941), dirigidos por Paul Călinescu-y ganadora de una Medalla por el film cultural- Noi / Terra di Roma, dirigido por Ion Cantacuzino (1942)-. Odessa in fiamme - producción Cineromit- iba a añadirse a esta trayectoria, siendo estrenada y galardonada en septiembre de 1942, siempre en Venecia y en presencia del ministro alemán Goebbels (A.S. LUCE).

\section{Reflejos de la guerra: Odessa in fiamme}

Odessa in fiamme lleva la firma del director de cine Carmine Gallone (18861973), prolífico autor de cine histórico - cabe mencionar Últimos días de Pompeya (1926), Escipión el Africano (1937)-y de cine musical -recordamos Giuseppe Verdi 
(1938) y El sueño de Butterfly (1939), películas en las que elige como protagonista a la soprano María Cebotari (1910-1949), diva internacional de origen rumano. A ella le asignó también el papel protagonista en Odessa in fiamme, siendo este personaje el eje vertebrador del guion-.

La película refiere dos historias que se entrelazan entre sí: una individual -de una familia burguesa de Chisinau- y otra colectiva - de la segunda conflagración, en el arco temporal que va desde el 28 de junio de 1940 hasta el 16 de octubre de 1941, en un flujo vectorial progresivo-. La idea cardinal de la trama argumental radica en la victoria del bien sobre el mal, del Eje sobre los rusos. El tratamiento del tema es, en cambio, «típicamente galloniano».

Tres son los episodios que se delinean: la separación, el viaje y la restauración de la situación inicial, una vez derrotado el antihéroe. Los episodios indicados se organizan en diez secuencias, demarcadas principalmente por los fundidos encadenados y la elipsis.

1) La primera secuencia -del planteamiento- congrega varios cuadros. El contrapunto del exordio -la voz de María Teodorescu (Maria Cebotari), interpretando (fuera de campo) el aria Salve d'amor de la ópera Tannhäuser de Richard Wagner, que acompaña la imagen de las llamas- aporta dramatismo, condensa la trama y vaticina el desenlace. La analogía con la ópera señala la música como recurso estilístico que encierra significados subyacentes. En la intimidad de su hogar, María le cuenta a su hijo la leyenda del emperador Trajano, «fundador de la nación rumana» (2:38 - 3:07), insertándose de esta forma uno de los tantos clichés destinados a subrayar la perduración milenaria de la fraternidad italiano-rumana, luego comprobada en los campos de batalla de la Segunda Guerra Mundial. Como esposa, María hace esfuerzos para aguantar el adulterio del marido Michelle (Carlo Ninchi).

2) La siguiente secuencia marca la intriga. Mientras el marido planea una escapada amorosa a Bucarest, ella luce en una fiesta popular en las afueras de Chisinau. De la fusión de música, trajes y bailes folclóricos resultan imágenes con innegable valor etnológico y sociológico, que superan la condición de mero procedimiento de transición entre los varios registros de la película. La coreografía de Floria Capsali (Dumitrescu 1985) y la música de Ion Vasilescu (Frost 1968) son detalles no faltos de importancia a la hora de juzgarlas. Pero la fiesta campestre, con el famoso baile Hora Unirii -símbolo de la unidad del Gran Reino de Rumanía-, acaba repentinamente con la noticia de la invasión soviética en Besarabia.

3) De la alegría ancestral transmitida a través del folclore se pasa a la resignada marcha de los deportados rumanos de Besarabia. María regresa a Chisinau, encuentra su casa vacía y los muros sellados con el símbolo comunista: la hoz y el marti1lo. Los bolcheviques habían secuestrado ya a su hijo, junto con otros futuros reclutas del Ejército Rojo que iban a recibir la educación del homo sovieticus. El marido -personaje en constante evolución, que tiende a catequizar con su metamorfosis-, enterado de lo ocurrido y preso de remordimientos, se alista en el ejército rumano.

4) Los nuevos dueños de Besarabia, representantes del NKVD (el Comisariado del Pueblo para Asuntos Internos), convierten a María en artista del pueblo soviético, como forma de chantaje para que le sea devuelto el hijo. Paulatinamente, se 
desarrollan escenas clave que resaltan el antagonismo de los beligerantes: la fe de los rumanos versus el ateísmo de los rusos que les impiden a rezar y recurren a métodos inhumanos a fin de metamorfosear a los súbditos, reducidos a números, en «perfectos bolcheviques» con el cordón umbilical cortado: «Se è piccolo, crescerà; se è malato guarirà; importante è che diventi un perfetto bolscevico» $(27: 27$ 27:40), replica un camarada. La matrícula 778 era el hijo de María, cautivo en Odessa (36:52), tal vez un eco kafkiano en la película de Carmine Gallone.

5) En un vagón repleto de deportados rumanos, María se dirige hacia Odessa y lamenta con su canto -doina Curge Nistrul lin la vale- el destino de su pueblo. Pero es burdamente silenciada por un soldado soviético, por haber cantado una canción prohibida por la censura. En los cafés de Odessa tendrá que cantar únicamente canciones aceptadas por las autoridades soviéticas, mientras sus connacionales estarán reclusos en el lager. Sería esta una sutil reflexión sobre el destino del artista bajo un régimen totalitario. Camine Gallone vuelve a emplear la música para transmitir el significado de la acción. La música que interpreta María alterna con símbolos de la potestad rusa: el ruido monótono e impasible del tren, el ruido espantoso del coche negro de los agentes NKVD o el ruido de los fusilamientos en masa.

6) Mientras tanto, el ejército rumano logra recuperar Besarabia y continúa la marcha hacia Odessa. En la película de ficción se insertan cuadros de los noticiarios y documentales (41:50). Destacan las imágenes del documental Războiul nostru sfânt (Nuestra guerra santa, 1941).

7) En un despertar de conciencia, al ordenar sentencias capitales en masa, Sergei Smirnof (Filippo Scelzo) - personaje lleno de contrastes, desde hace tiempo enamorado de la música y de María y espeluznante representante local de NKVD- revela unas reminiscencias de su humanidad abrumada por el régimen totalitario, negándose a firmarlas. Y esto a pesar de las insistencias de Luba (Olga Solbelli), prototipo estereotipado de la mujer combatiente $(51: 10$ - 53:10), una especie de títere de la ideología soviética que no hesitará en disparar al vacilante comisario Sergei al final. Un encuadre contrapicado pone de relieve su prepotencia, mientras que entre los objetos expresivos que la retratan destacan las típicas botas soviéticas.

8) En el camino del ejército rumano hacia Odessa, el capitán Michelle Teodorescu, improvisando una fuente bautismal de un casco militar, bautiza a un niño ruso antes de morir. Y siguen otros bautismos de pequeños rusos. Se exaltan así los rasgos de los rumanos: la fe, la piedad, la empatía.

9) Siguen los bombardeos del Eje sobre Odessa. Una vez más, imágenes de los noticiarios y de los documentales de la ONC y LUCE se intercalan en la película de ficción: el documental Războiul nostru sfânt (1941) y el noticiario L'ocupazione della citta da parte delle truppe romene (1942). El ritmo se vuelve más rápido, la duración de los planos más corta, la concatenación de las imágenes más alerta, los recursos sonoros más expresivos -el ruido de los aeroplanos, el fragor de los bombardeos-. Grandes planos generales, que muestran el escenario bélico, lucen la pequeñez del hombre frente a la máquina de guerra.

10) La analogía con la Tosca de Puccini resulta patente una vez más: María, dispuesta a ceder a las propuestas amorosas de Sergei, a cambio de salvar a su hijo de las catacumbas de Odessa, abandona el espectáculo de ópera y se dirige hacia el 
puerto para escaparse los tres. En su desesperada huida baja la famosa escalera de Odessa (1:12:10 - 1:12:25), vuelta antológica en la modélica película El acorazado Potemkin (Serguéi Eisenstéin, 1925), una intertextualidad rebuscada con la celebérrima película de propaganda a la cual Carmine Gallone le rinde homenaje. Mientras Odessa cae, María, el marido y el hijo se reúnen y el cielo se vislumbra: «Si vede il cielo» -replica el pequeño Nico (Maurizio Romitelli)-. La película se desenlaza con la marcha triunfal del ejército rumano y el desmantelamiento de la estrella roja, símbolo del poder soviético.

\section{Epílogo}

El epílogo de los tres apartados se reduce a una sola idea: no hay guerra sin propaganda y el cine es parte de la «fabrica del consenso» (Cannistraro 1972). La idea de que el espectador deba recibir mensajes patrióticos envueltos en una ficción anima a ambos bandos: las potencias del Eje y los Aliados. Es digno de señalar que el cine bélico de los Aliados cuenta con famosos directores de cine: los estadounidenses Frank Capra (Why we fight, 1942) y Lewis Milestone (The North Star, 1943); los británicos Michael Powell y Emeric Pressburger (One of Our Aircraft Is Missing, 1942; The volunteer, 1943); los rusos Leonid Varlámov e Iliá Kopalin (Moscú contraataca, 1942) etc. Cabe desde luego recordar que la función del cine documental como medio de propaganda se fundamenta en Gran Bretaña, con la escuela de John Grierson.

Como obra de su tiempo, Odessa in fiamme sigue por lo tanto las pautas de la lucha entre el bien y el mal, hace hincapié en los antagonismos, inculca el sentimiento de pertenecer a una nación, moldea conciencias y construye el consenso. El recorrido de sus personajes marca un devenir y se vuelve en exemplum combatiendo por un ideal legítimo. Pero más allá de los axiomáticos condicionamientos ideológicos, explícitos o implícitos, esta película alcanza un valor estético conferido por el guion, el lenguaje fílmico y los elementos estilísticos: plausible la narración, fidedignos los diálogos (a excepción de la leyenda de Trajano y unas cuantas frases hechas en el laboratorio doctrinal), acertada la elección de los nombres, subrayados los rasgos antinómicos de los personajes, convincente la interpretación de los actores, verídicos los escenarios (internos - los estudios de Cinecittà, Roma-; externos -Bucarest, Chisinau, Odessa-); expresivo el lenguaje visual (el juego de luces y sombras), sonoro (la mezcla de música y ruidos) y también expresivos los movimientos de cámara.

En conclusión, Odessa in fiamme no es simplemente un film de propaganda, sino una película colocada en la frontera de los géneros histórico, documental y musical. Para los oficiales alemanes de la época indicaba la orientación de la política cinematográfica rumana hacia Italia. Para los cineastas rumanos sigue figurando un destino cruelmente truncado: después de que el país fuera asignado a la esfera de influencia soviética, con el notorio «acuerdo de los porcentajes», Cineromit no perduró (Lazăr y Spila 2003) y sobre Odessa in fiamme cayó el velo del olvido por seis décadas. 


\section{Referencias bibliográficas}

Archivio Storico LUCE - Cronaca della X Mostra del Cinema. L arrivo del ministro Goebbels - C0278, 8/09/1942; L'ocupazione della citta da parte delle truppe romene - Giornale LUCE C0194, 6/11/1941.

ARGENTIERI, Mino (1977): L'occhio del regime. Informazione e propaganda nel cinema del fascismo. Firenze: Vallecchi.

- (1986): L'asse cinematografica Roma-Berlino. Napoli: Edizioni Libreria Sapere.

Arhivele Naţionale Istorice Centrale, București. Fond Ministerul Propagandei Naţionale, Presa internă, dosar 601; Adrian Corbu, dosar 125.

BrunetTA, Gian Piero (1975): Cinema italiano tra le due guerre. Fascismo e politica cinematografica. Milano: Mursia.

BurCEA, Carmen (ed.) (2008): Romania nei dossier Minculpop, Racolta di documenti. București: Editura Institutului de Științe Politice și Relații Internaționale.

CANNISTRARO, Philip (1972): «Il cinema italiano sotto il fascismo». Storia contemporanea, Rivista trimestrale di studi storici 3: 413-465.

CANTACUZINO, Ion (1965): Momente din trecutul filmului românec. București: Editura Meridiane.

- (1997): Intâlniri cu cinematograful, amintiri. București: Editura Alo.

CONSTANTINIU, Florin (1997): O istorie sinceră a poporului român. București: Univers Enciclopedic.

DuMitrescu, Mitiţă (1985): Amintiri despre Floria Capsali. Bucureşti: Editura Muzicală.

Frost, Ana (1968): Ion Vasilescu: poet al melodiei. București: Editura Muzicală.

Gallone, Carmine (dir.) (1942): Odessa in fiamme/ Cătușe roșii. Italia-Rumanía: Grandi Film Storici \& ONC. Guion: Nicolae Kirițescu, Gherardo Gherardi. Actores principales: María Cebotari, Filippo Scelzo, Carlo Ninchi, Olga Solbelli. Gran Premio del Festival de Cine de Venecia 1942.

Hull, David Stewart (1969): Film in the Third Reich. A Study of the German Cinema 19331945. Berkeley: University of California Press.

GoebBELS, Joseph (1984): I diari di Goebbels 1939-1941. Milano: Sperling \& Kupfer Editori.

KraKaUer, Siegfried (1947): From Caligari to Hitler. A Psychological History of the German Film. London: Princeton University Press.

LAZĂR, Veronica, y SPILA, Piero (ed.) (2003): Cineromit. Il sogno della Cinecitta romena 1941-1946. Roma: Associazione Itaro Arte.

SAdOUL, Georges (1961): Historia cinematografului mondial. De la origini până în zilele noastre. București: Editura Științifică. 